\title{
Etanercept in juvenile idiopathic arthritis: Who will benefit?
}

\author{
MH Otten ${ }^{1 *}$, FHM Prince ${ }^{1}$, W Armbrust ${ }^{2}$, R ten Cate ${ }^{3}$, EPAH Hoppenreijs ${ }^{4}$, M Twilt ${ }^{1,3}$, Y Koopman-Keemink ${ }^{5}$, \\ SL Gorter ${ }^{6}$, KM Dolman ${ }^{7}$, JF Swart ${ }^{7}$, JM van den Berg ${ }^{7}$, NM Wulffraat ${ }^{8}$, MAJ van Rossum ${ }^{7}$, LWA van Suijlekom-Smit ${ }^{1}$ \\ From 18th Pediatric Rheumatology European Society (PReS) Congress \\ Bruges, Belgium. 14-18 September 2011
}

\section{Background}

The pharmacological treatment approach for juvenile idiopathic arthritis (JIA) has changed substantially since the introduction of biologicals, with nowadays inactive disease as realistic treatment goal.

\section{Aim}

To identify factors at baseline which predict etanercept treatment response and subsequently optimize treatment strategies.

\section{Methods}

The Arthritis and Biologicals in Children Register (observational study, ongoing since 1999), includes all Dutch JIA-patients who used etanercept. Disease activity variables were retrieved prospectively at start of treatment, after 3 months, and yearly thereafter.

\section{Results}

262 previously biologic-naive JIA-patients initiated etanercept; $71 \%$ female, $18 \%$ systemic-onset subtype. Median age at onset 6.9 (IQR 3.6-11.1) years, median followup 35.6 (IQR 17.4-53.6) months. In the long-term, the overall majority responded to etanercept and up to $40 \%$ reached inactive disease. Excellent response after 15 months (85 patients, $32 \%$ ) was associated with low baseline disability (OR 0.49/point increase, 95\%CI 0.33-0.74), fewer DMARDs used before etanercept (OR 0.64/ DMARD used, 95\%CI 0.43-0.95) and younger age at onset (OR 0.92/year, 95\%CI 0.84-0.99); poor response (88 patients, 34\%) was associated with female gender (OR 2.12, 95\%CI 1.11-4.08) and systemic-onset subtype
(OR 3.24, 95\%CI 1.39-7.56). However, 24\% of systemiconset patients reached excellent response. Reasons for discontinuation: ineffectiveness in 78, adverse events (AEs) in 25, remission in 39 patients. Etanercept was well tolerated. Patients who developed AEs could not be identified at baseline.

\section{Conclusions}

Excellent response was associated with baseline low disability and less DMARD-use before etanercept. Therefore, the focus should be on strategies with early introduction of etanercept to improve outcomes for JIA. The role of etanercept for the systemic-onset subtype remains debatable.

\section{Author details \\ ${ }^{1}$ Department of Pediatrics/Pediatric Rheumatology, Rotterdam, The Netherlands. ${ }^{2}$ Department of Pediatrics/Pediatric Rheumatology, Groningen, The Netherlands. ${ }^{3}$ Department of Pediatrics/Pediatric Rheumatology, Leiden, The Netherlands. ${ }^{4}$ Department of Pediatrics/Pediatric Rheumatology, Nijmegen, The Netherlands. ${ }^{5}$ Department of Pediatrics/Pediatric Rheumatology, The Hague, The Netherlands. 'Department of Pediatrics/ Pediatric Rheumatology, Maastricht, The Netherlands. ${ }^{7}$ Department of Pediatrics/Pediatric Rheumatology, Amsterdam, The Netherlands. \\ ${ }^{8}$ Department of Pediatrics/Pediatric Rheumatology, Utrecht, The Netherlands.}

Published: 14 September 2011

doi:10.1186/1546-0096-9-S1-O28

Cite this article as: Otten et al.: Etanercept in juvenile idiopathic arthritis: Who will benefit? Pediatric Rheumatology 2011 9(Suppl 1):O28.

\footnotetext{
* Correspondence: m.otten@erasmusmc.nl

'Department of Pediatrics/Pediatric Rheumatology, Rotterdam, The Netherlands

Full list of author information is available at the end of the article
}

(c) 2011 Otten et al; licensee BioMed Central Ltd. This is an open access article distributed under the terms of the Creative Commons 